\title{
Effects of type 1 diabetes mellitus on lumbar disc degeneration: a retrospective study of 118 patients
}

\author{
Rui Chen ${ }^{1 \dagger}$, Xinjie Liang ${ }^{2 \dagger}$, Tianji Huang ${ }^{3}$, Weiyang Zhong ${ }^{3^{*}}$ (D) and Xiaoji Luo ${ }^{3^{*}}$
}

\begin{abstract}
Background: The study aimed to investigate the correlation between type 1 diabetes (T1D) and lumbar disc degeneration (LDD).

Methods: A retrospective analysis of 118 patients with T1D recruited from January 2014 to March 2019 was performed, and multivariate logistic regression was used to analyse the incidence of T1D; the age, sex, and body mass index (BMI) of the patients; the disease duration and the glycosylated haemoglobin and venous blood glucose levels. All patients who suffered low back pain were assessed by MRI using the Pfirrmann grading system.
\end{abstract}

Results: A total of 118 patients with an average age of $36.99 \pm 17.01$ (8-85 years) were reviewed. The mean hospitalization duration, venous glucose fluctuation range, glycated haemoglobin level, highest venous glucose level, venous glucose level, and disease course duration were $13.98 \pm 10.16$ days, $14.99 \pm 5.87 \mathrm{mmol} / \mathrm{L}$, $9.85 \pm 2.52 \mathrm{mmol} / \mathrm{L}, 25.29 \pm 7.92 \mathrm{mmol} / \mathrm{L}, 13.03 \pm 5.75 \mathrm{mmol} / \mathrm{L}$ and $7.30 \pm 8.41$ years. The average Pfirmann scores of the different discs were $2.20 \pm 0.62(\mathrm{~L} 1-2), 2.35 \pm 0.67(\mathrm{~L} 2-3), 2.90 \pm 0.45(\mathrm{~L} 3-4), 4.20 \pm 0.52$ (L4-5) and $4.10 \pm 0.72$ (L5-S1). The patients with T1D showed severe disc degeneration. The male sex, glycosylated haemoglobin, venous glucose and venous glucose fluctuations were significantly associated with LDD $(P<0.05)$.

Conclusions: Glycosylated haemoglobin, the male, venous glucose and the venous glucose fluctuation range were risk factors for LDD.

Keywords: Type 1 diabetes, Lumbar disc degeneration, Risk factor

\footnotetext{
*Correspondence: 492467112@qq.com; cy2982@163.com

${ }^{\dagger}$ Rui Chen and Xinjie Liang contributed equally to this work.

${ }^{3}$ Department of Orthopedic Surgery, The First Affiliated Hospital of Chongqing Medical University, Chongqing 400016, P. R. China

Full list of author information is available at the end of the article
}

(c) The Author(s). 2020 Open Access This article is licensed under a Creative Commons Attribution 4.0 International License, which permits use, sharing, adaptation, distribution and reproduction in any medium or format, as long as you give appropriate credit to the original author(s) and the source, provide a link to the Creative Commons licence, and indicate if changes were made. The images or other third party material in this article are included in the article's Creative Commons licence, unless indicated otherwise in a credit line to the material. If material is not included in the article's Creative Commons licence and your intended use is not permitted by statutory regulation or exceeds the permitted use, you will need to obtain permission directly from the copyright holder. To view a copy of this licence, visit http://creativecommons.org/licenses/by/4.0/ The Creative Commons Public Domain Dedication waiver (http://creativecommons.org/publicdomain/zero/1.0/) applies to the data made available in this article, unless otherwise stated in a credit line to the data. 


\section{Background}

Diabetes mellitus (DM) is a common disease with a worldwide incidence rate of approximately $8 \%$. There are 1.14 million diabetic patients, and the annual rate of increase is 1.2 million; $5 \%$ of these patients have type 1 diabetes (T1D) [1-5]. T1D is an autoimmune disease in which beta cells that produce insulin are destroyed. Furthermore, because of the early onset, T1D can affect many organs, including the bone and cartilage, and these changes result in catabolic and anabolic unbalanced responses that lead to intervertebral disc degeneration [6-8]. Hyperglycaemia can cause metabolic disorders of carbohydrates, proteins and other substances, as well as microvascular disease, resulting in insufficient nutrient supply to the intervertebral discs. Furthermore, T1D may contribute to intervertebral disc degeneration by promoting aggrecan degradation and apoptosis. LDD is a major cause of low back pain and leg pain, which can cause health problems for individuals and affect their daily life and work $[9,10]$.

Previous studies have focused on the relationship between type $2 \mathrm{DM}$ and LDD and concluded that $\mathrm{DM}$ is a risk factor for LDD, and that DM is related to spinal stenosis [6-10]. Due to T1D being an immune disease with an early onset time and glucose control being difficult, T1D can result in early degeneration of the intervertebral disc (IVD). In our study, we investigated the relationship between T1D and LDD assessed by the Pfirrmann scoring system with MRI.

\section{Materials and methods Study design}

This study was approved by the Institutional Review Board of the First Affiliated Hospital of Chongqing Medical University and conducted according to the principles of the Declaration of Helsinki. All the patients provided written informed consent to participate in our study prior to the storage of their data in the hospital database.

Patients recruited from January 2014 to March 2019 were reviewed retrospectively. The inclusion criteria were adults with (1) symptoms of diabetes and diabetic ketosis that occurred within 6 months of the onset of diabetes, (2) insulin-dependent therapy and (3) fasting $\mathrm{C}$ peptide (FCP) and postprandial $\mathrm{C}$ peptide $(\mathrm{PCP})$ levels of $\leq 200 \mathrm{pmol} / \mathrm{L}$ and $\leq 400 \mathrm{pmol} / \mathrm{L}$, respectively. The exclusion criteria were patients with type 2 DM, gestational diabetes, fulminant type 1 diabetes, adult occult autoimmune diabetes, adolescent adult diabetes, mitochondrial diabetes, or other special types of diabetes and patients suffering from serious non-diabetic related heart, liver, kidney or other organ-related diseases.
Table 1 Demographic data

\begin{tabular}{ll}
\hline Index & Values \\
\hline Age & $36.99 \pm 17.01(8-85)$ \\
Male/female $(n)$ & $61 / 57$ \\
Hospitalization duration (d) & $13.98 \pm 10.16$ \\
Venous glucose fluctuation range (mmol/L) & $14.99 \pm 5.87$ \\
Glycated haemoglobin (mmol/L) & $9.85 \pm 2.52$ \\
Highest venous glucose (mmol/L) & $25.29 \pm 7.92$ \\
Venous glucose (mmol/L) & $13.03 \pm 5.75$ \\
Disease course (y) average & $7.30 \pm 8.41$ \\
Pfirrmann scores & \\
L1-2 & $2.20 \pm 0.62$ \\
L2-3 & $2.35 \pm 0.67$ \\
L3-4 & $2.90 \pm 0.45$ \\
L4-5 & $4.20 \pm 0.52$ \\
L5-S1 & $4.10 \pm 0.72$ \\
\hline
\end{tabular}

\section{Outcome assessments}

LDD grading was performed independently by an experienced spine surgeon with standard T2-weighted turbo spin-echo sagittal images and the five-level Pfirrmann grading system [11].

\section{Statistical analysis}

The statistical analysis was performed using the Statistical Analysis Software (SAS Institute Inc., Cary, NC, USA). Quantitative variables were described as the mean \pm SD. Regression analysis was used to identify the relationship between T1D and LDD. Differences with a $P$ value of $<0.05$ were considered significant.

\section{Results}

A total of 118 patients with an average age of $36.99 \pm$ 17.01 (8-85 years) were reviewed (Table 1 ). The mean hospitalization duration, venous glucose fluctuation range, glycated haemoglobin level, highest venous glucose level, venous glucose level and disease course duration which was $13.98 \pm 10.16$ days, $14.99 \pm 5.87$ $\mathrm{mmol} / \mathrm{L}, \quad 9.85 \pm 2.52 \mathrm{mmol} / \mathrm{L}, 25.29 \pm 7.92 \mathrm{mmol} / \mathrm{L}$, $13.03 \pm 5.75 \mathrm{mmol} / \mathrm{L}$ and $7.30 \pm 8.41$ years. The average Pfirrmann scores of the different discs were $2.20 \pm 0.62$ (L1-2), $2.35 \pm 0.67$ (L2-3), $2.90 \pm 0.45$ (L3-4), $4.20 \pm$ 0.52 (L4-5) and $4.10 \pm 0.72$ (L5-S1) (Table 1).

The male sex, glycosylated haemoglobin, venous glucose and venous glucose fluctuations were significantly associated with $\operatorname{LDD}(P<0.05)$ (Table 2$)$. Regression analysis indicated that these factors have a linear relationship with LDD (Figs. 1, 2, 3, 4 and 5). 
Table 2 Regression analysis between T1D and LDD

\begin{tabular}{|c|c|c|c|c|c|c|}
\hline Index & $B$ value & $\begin{array}{l}\text { Standard } \\
\text { value }\end{array}$ & Wald & OR & $\begin{array}{l}\text { 95\%confidence } \\
\text { interval }\end{array}$ & $P$ value \\
\hline Age & 0.042 & 0.020 & 4.273 & 1.043 & $1.002-1.085$ & 0.061 \\
\hline Male sex & 1.232 & 0.583 & 4.469 & 3.428 & $1.094-1.743$ & 0.035 \\
\hline $\begin{array}{l}\text { Venous } \\
\text { glucose fluctuation range }(\mathrm{mmol} / \mathrm{L})\end{array}$ & 0.120 & 0.056 & 4.537 & 1.127 & $1.010-1.259$ & 0.033 \\
\hline Glycated haemoglobin (mmol/L) & 0.300 & 0.131 & 5.247 & 1.350 & $1.044-1.745$ & 0.022 \\
\hline Highest venous glucose $(\mathrm{mmol} / \mathrm{L})$ & -0.026 & 0.034 & 0.576 & 0.974 & $0.911-1.042$ & 0.448 \\
\hline Venous glucose (mmol/L) & 0.146 & 0.053 & 7.674 & 1.157 & $1.044-1.283$ & 0.036 \\
\hline $\mathrm{BMI}$ & 0.184 & 0.125 & 2.162 & 1.202 & $0.952-1.537$ & 0.141 \\
\hline
\end{tabular}

\section{Discussion}

T1D is considered an autoimmune disease that affects individuals from a young age and requires insulindependent treatment due to defects in insulin secretion in the individual. It has a tendency to ketoacidosis. Long-term chronic hyperglycaemia in individuals with T1D is associated with chronic complications, which are a threat to children and adolescents [12, 13]. Fifty percent of patients with T1D are adults, which has a large impact on social productivity and medical expenditures. T1D patients have relatively complicated treatment plans, a long course of disease and poor blood glucose control. According to the US Wisconsin Diabetes Registration Counseling Study data, only $1 \%$ of patients have high glycosylated haemoglobin (HbA1c) levels, while $<7 \%$ of the T1D patients in China have high HbA1c levels, leading to more challenge $s[14,15]$. Furthermore, in China, the clinical

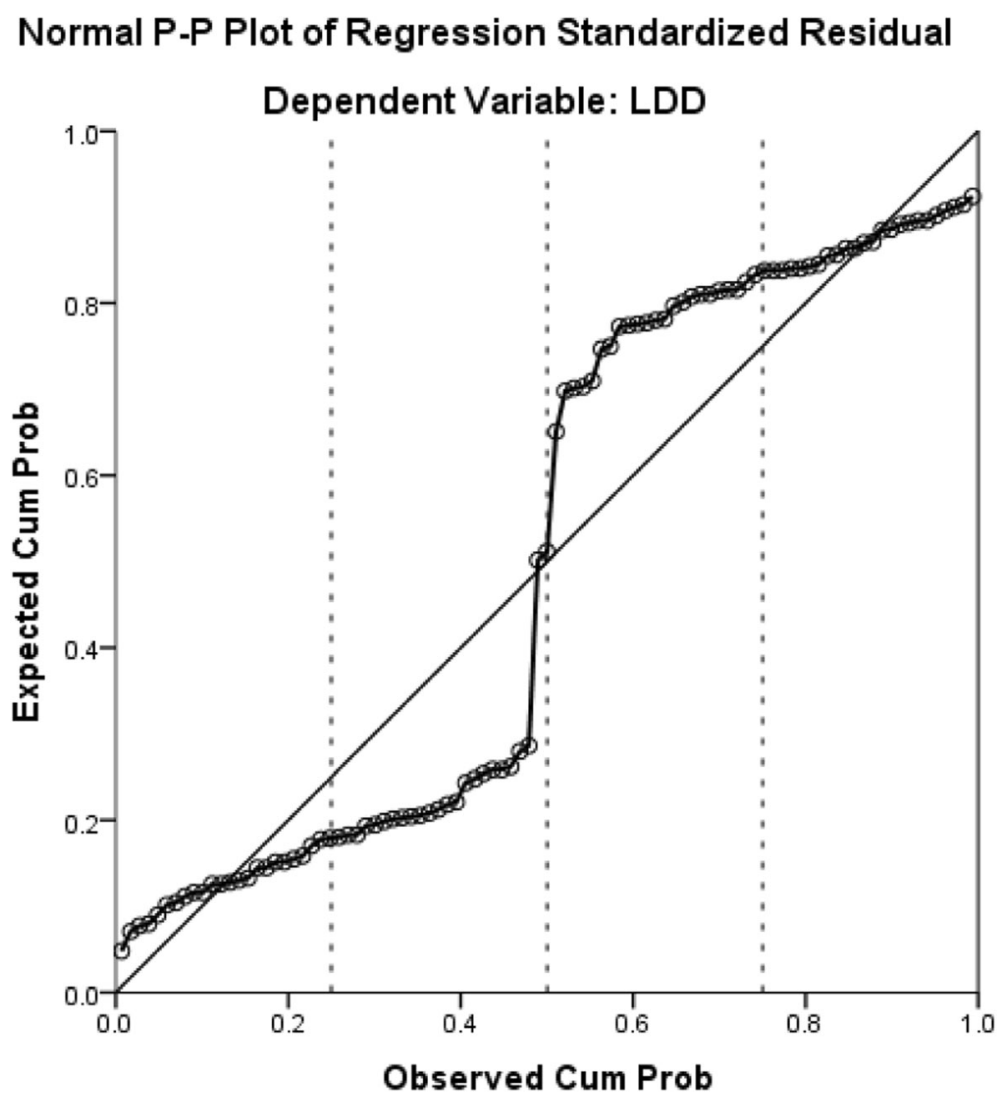

Fig. 1 The relationship between venous glucose and LDD. Cum Prob, cumulative probability 


\section{Normal P-P Plot of Regression Standardized Residual}

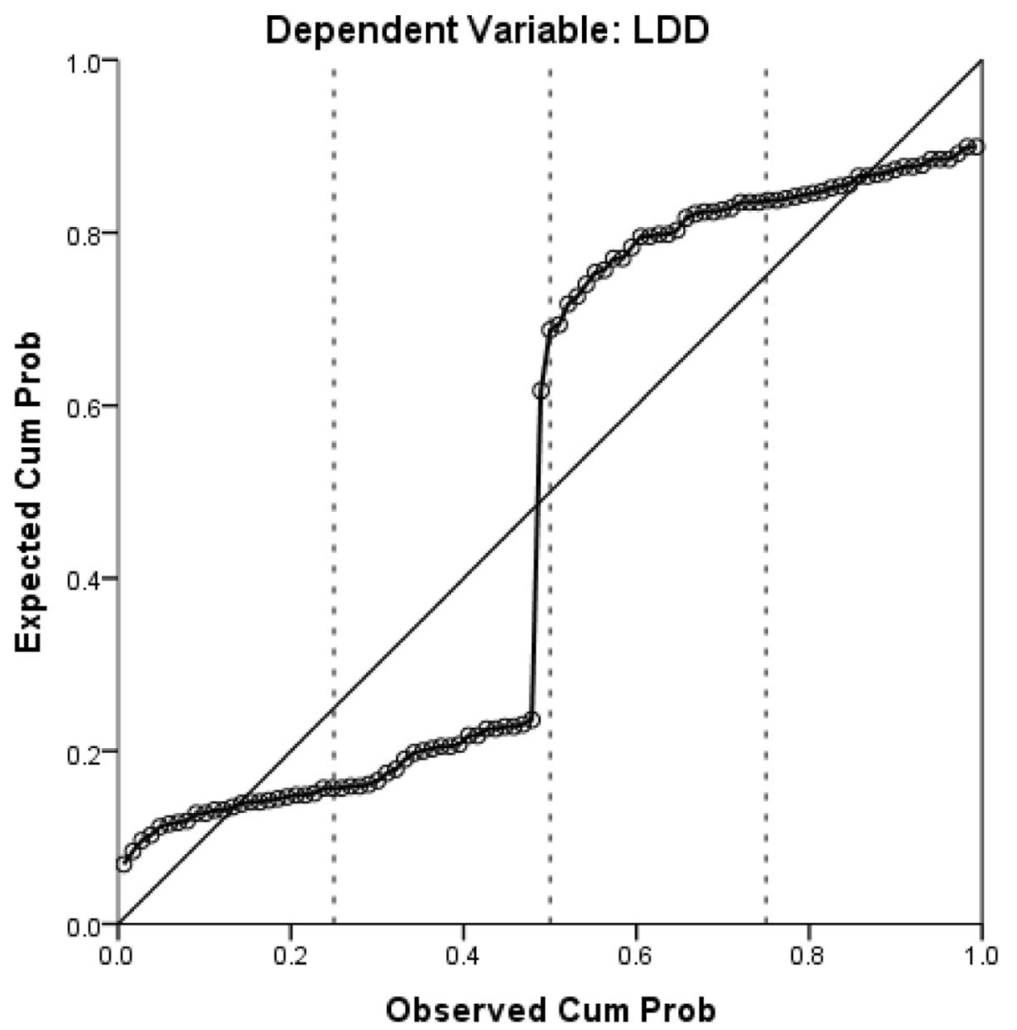

Fig. 2 The relationship between glycated haemoglobin and LDD

features are more atypical, and the risk of complications associated with diabetes is much higher, which should be addressed.

LDD can cause low back pain, affect patients' quality of life and increase medical expenses. Hence, it is very important to investigate the risk factors for LDD to prevent or delay its onset or progression. This study was the first to evaluate the association between T1D and LDD $[4,7,10]$. In previous studies, Hao et al., Mysliwiec LW et al. and Milette PC et al. [12-14] have found that the patients aged $40 \pm 4.6$ years had slight LDD in MRI, and $63.9 \%$ of the patients had $1.63 \pm 0.68$ of Pfirrmann scores while the average of Pfirrmann scores was $3.15 \pm$ 0.95 in our study. One study reported that patients with type 2 diabetes (T2D) had more tendency to develop more severe LDD than those without T2D. The T2D duration had a positive correlation with severity of LDD which mean the patients with a worse control of T2D showed more severe LDD than those with a good control [10].

In our study, the male sex, glycosylated haemoglobin, venous glucose and venous glucose fluctuations were significantly associated with LDD. The incidence of T1D in male patients was higher than that in female patients, and the male patients had poorer control of glucose. Of the patients with T1D, the patients with poor control of glucose had more severe disc degeneration. This result showed that T1D was a risk factor for LDD. It has been reported that DM patients have a poorer outcome following lumbar discectomy than patients without DM, and that high preoperative glycated haemoglobin levels and longterm DM are risk factors for poor cervical laminoplasty outcomes in patients with T2D and cervical spondylotic myelopathy [10].

Now, we can conclude that there is a positive relationship between T1D and LDD. However, the underlying mechanisms remain unclear. Previous studies have suggested that in a hyperglycaemic environment, nucleus pulposus (NP) cells stop producing or even begin to degrade proteoglycan and collagen II, resulting in a decreased intravertebral pressure and a disruption in the structural integrity of the nucleus, and that hyperglycaemia enhances the formation of advanced glycation end products (AGEs) in the NP, which also leads to the progression of disc degeneration. Some studies have found that autophagy in diabetic rats is significantly higher than that in control 


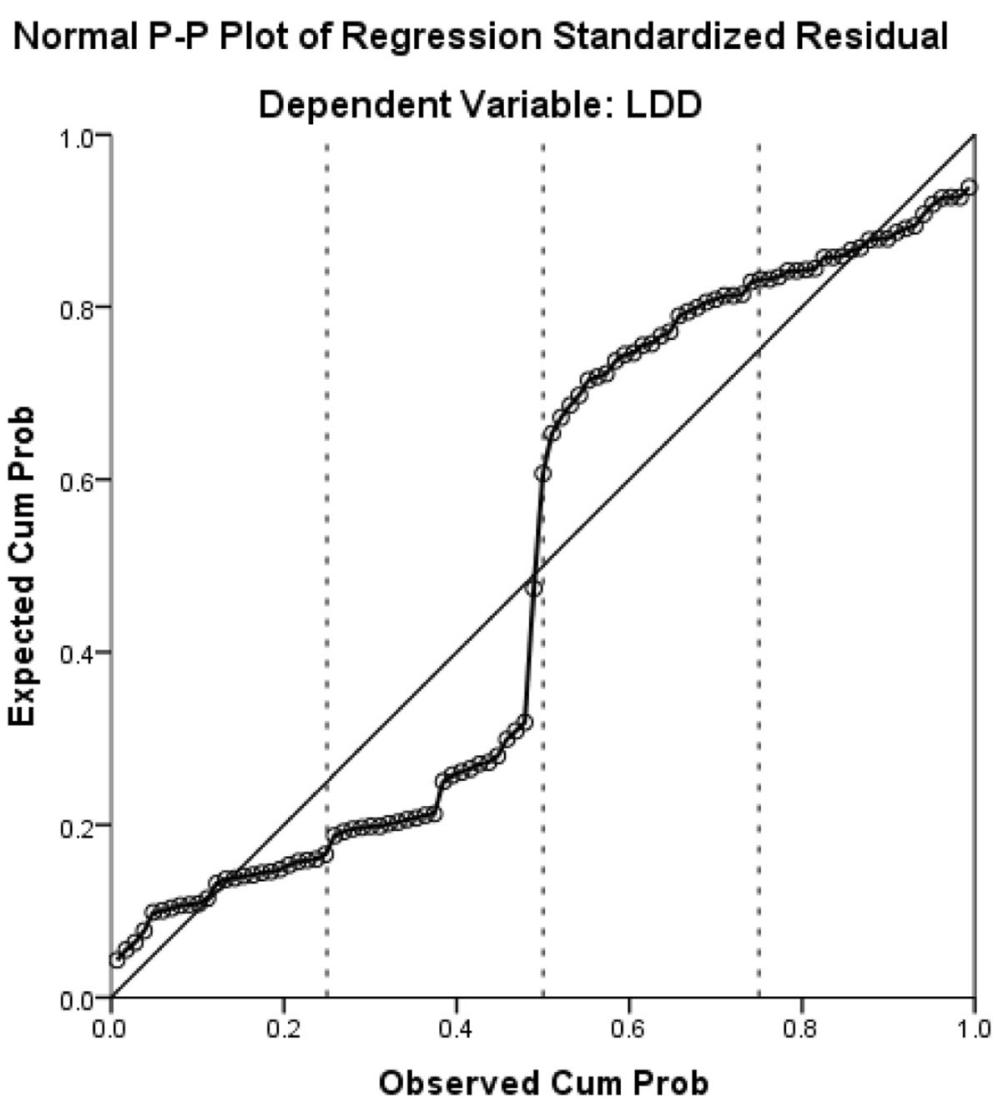

Fig. 3 The relationship between venous glucose fluctuation and LDD

rats, and it is believed that autophagy caused by hyperglycaemia can lead to degeneration in intervertebral disc cells [15-20]. Moreover, the microvessels of the vertebral endplates of diabetic animals are significantly narrowed, resulting in a decrease in blood supply and nutrition in the intervertebral disc. The vertebral endplate may become harder, further impairing its permeability to nutrients. This type of sclerosis is caused by the anabolic effects of DM on osteochondral metabolism [21-24]. Also, other studies found that high serum cholesterol and triglyceride levels are risk factors for atherosclerosis, which may be the cause of reduced blood supply to already poor vascularized IVD, and more understanding about IVD degeneration process was enhanced [25].

In our study, we also found that the average Pfirrmann scores in patients with poor control of DM indicated severe degeneration. For most patients with T1D, although good control of glucose is difficult, continuous adequate insulin therapy is essential. Not only is it able to maintain patients' glucose levels in the normal range, but it is also able to avoid acute or chronic complications. Furthermore, after insulin treatment for the T1D patients, we must know that IVD is a complex pathological process. Conservative treatments, such as lifestyle changes, physical therapy, painkillers and rehabilitation, often fail. Except surgical treatments, the biotherapy requires more attention and understanding as its goal is to prevent and manage IVD degeneration. However, clinical applications of biotherapy are still have a long way, and more animal and clinical studies are needed to elucidate the role of mesenchymal stem cells and the role of gene therapy in the prevention and treatment of IVD degeneration [26].

To our knowledge, this was the first study to investigate the relationship between T1D and LDH with MRI. However, we want to declare that there are several limitations in this study. First, all included patients in our study were experiencing low back pain. Second, we did not conduct basic research on how T1D affects LDH. Hence, in the future, basic research studies on genes related to degeneration in intervertebral discs should be performed.

\section{Conclusion}

Glycosylated haemoglobin, the male, venous glucose and venous glucose fluctuation range were risk factors for LDD. 


\section{Normal P.P Plot of Regression Standardized Residual}

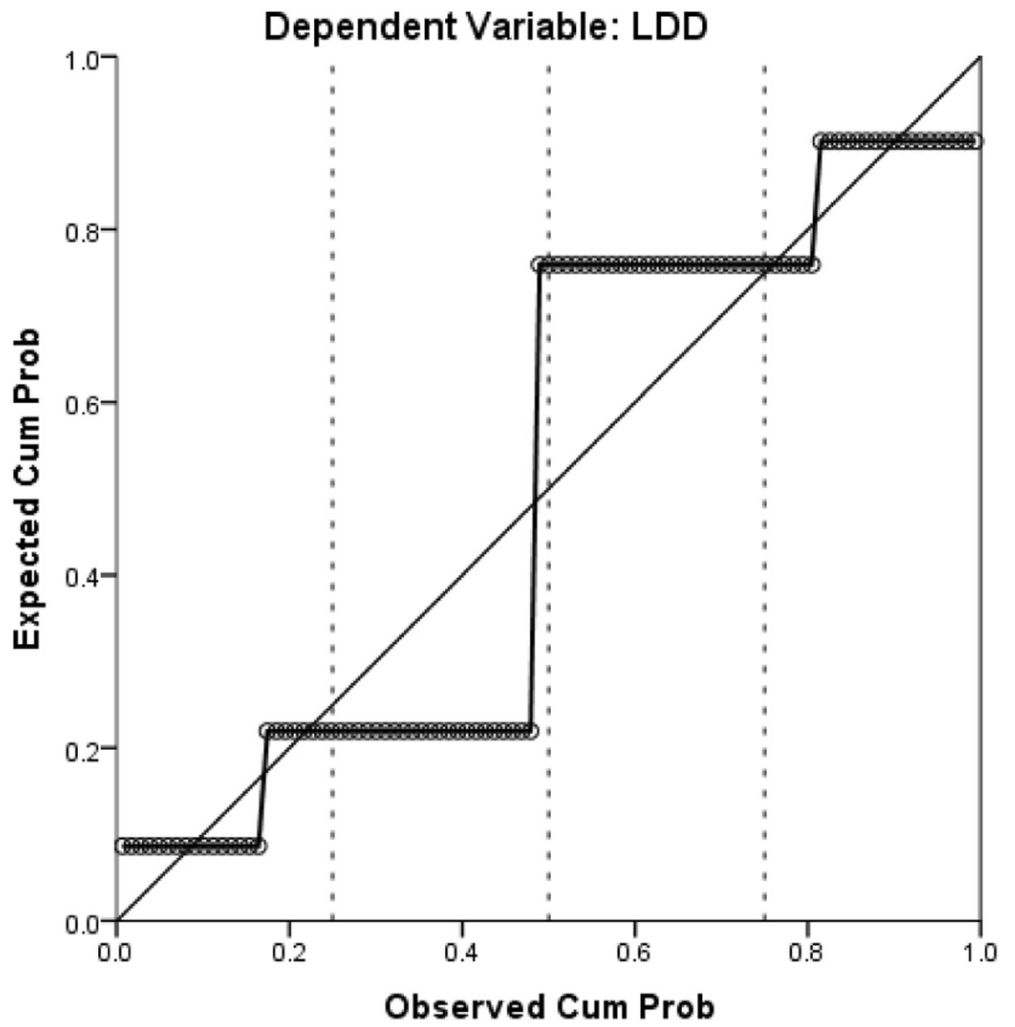

Fig. 4 The relationship between sex and LDD

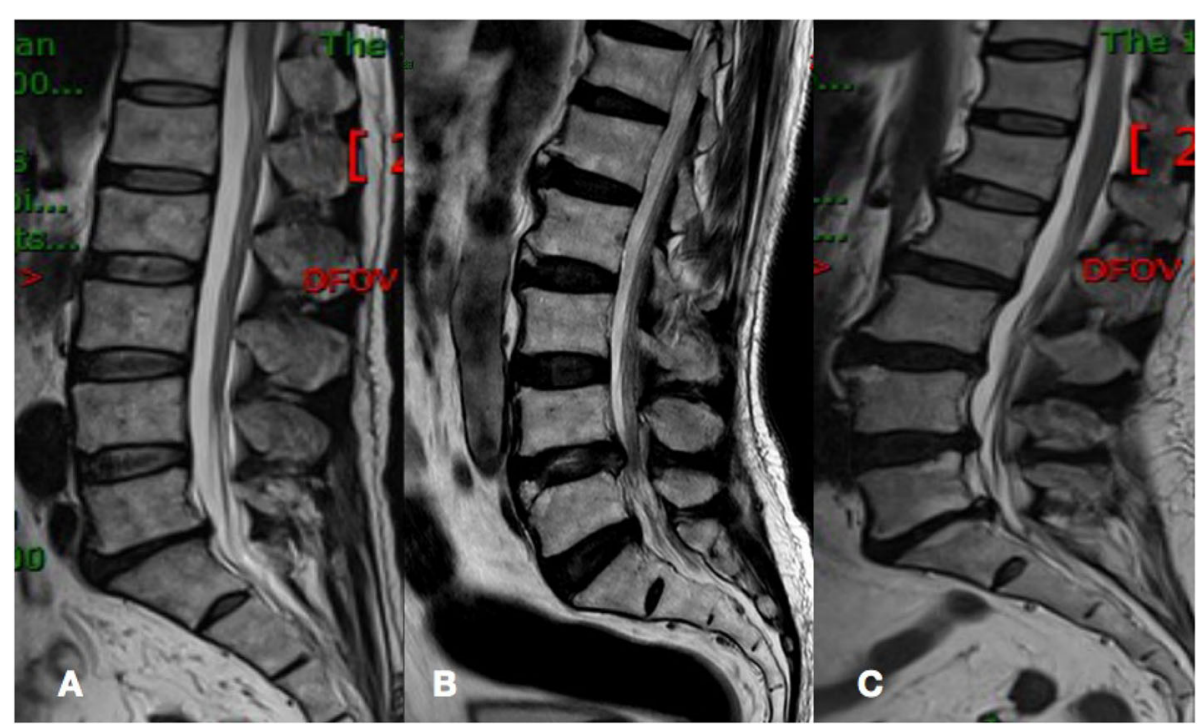

Fig. 5 a A 30-year-old female patient with T1D for 6 years suffering low back pain for 5 years. The Pfirrmann scores from $L 1 / 2$ to $L 4 / 5$ are all 3 , and L5/S1 are 4. $\mathbf{b}$ a 44-year-old male patient with T1D for 10 years suffering low back pain for 8 years. The Pfirrmann scores from L1/2 to L3/4 are all 4 , and from L4/5 to L5/S1 are 5. c a 57-year-old female patient with T1D for 16 years suffering low back pain for 15 years. The Pfirrmann scores of $L 1 / 2$ are 3 and from to $L 2 / 3$ to $L 3 / 4$ are all 4 and from $L 4 / 5$ to $L 5 / S 1$ are 5 


\section{Abbreviations}

T1D: Type 1 diabetes; LDD: Lumbar disc degeneration; BMI: Body mass index; DM: Diabetes mellitus; IVD: Intervertebral disc; FCP: Fasting C peptide; PCP: Postprandial C peptide; BP: Nucleus pulposus; AGEs: Advanced glycation end products; T2D: Type 2 diabetes

\section{Acknowledgements}

Not applicable.

\section{Authors' contributions}

WYZ and XJiL designed the study. RC and XJieL collected the data. RC, XJieL, $\mathrm{XJiL}$ and TJH performed the statistical analysis and drafted and revised the manuscript. WYZ revised the manuscript. All authors read and approved the final manuscript.

\section{Funding}

The study was supported by the hospital training funding (PYJJ2019-08).

\section{Availability of data and materials}

The datasets generated and/or analysed during the current study are not publicly available due to the data is confidential patient data but are available from the corresponding author on reasonable request.

\section{Ethics approval and consent to participate}

The Institutional Review Board of the First Affiliated Hospital of Chongqing Medical University approved this study and conducted in accordance with the Declaration of Helsinki. All participants provided written informed consent before their data were stored in our hospital database and used for study purposes.

\section{Consent for publication}

Not Applicable.

\section{Competing interests}

The authors declare that they have no competing interests.

\section{Author details}

'Department of Neurology, The First Affiliated Hospital of Chongqing Medical University, Chongqing 400016, P. R. China. ${ }^{2}$ Department of Pain Management, The First Affiliated Hospital of Chongqing Medical University, Chongqing 400016, P. R. China. ${ }^{3}$ Department of Orthopedic Surgery, The First Affiliated Hospital of Chongqing Medical University, Chongqing 400016, P. R. China.

Received: 3 March 2020 Accepted: 6 July 2020

Published online: 25 July 2020

\section{References}

1. Sakellaridis $\mathrm{N}$. The influence of diabetes mellitus on lumbar intervertebral disk herniation. Surg Neurol. 2006;66:152-4.

2. Lotan R, Fau OA, Anekstein Y, et al. Lumbar stenosis and systemic diseases: is there any relevance? J Spinal Disord Tech. 2008;21:247-51.

3. Anekstein Y, Fau SY, Lotan $R$, et al. Diabetes mellitus as a risk factor for the development of lumbar spinal stenosis. Isr Med Assoc J. 2010;12:16-20.

4. Illien-Junger S, Lu Y, Qureshi SA, Hecht AC, Cai W, Vlassara H, et al. Chronic ingestion of advanced glycation end products induces degenerative spinal changes and hypertrophy in aging pre-diabetic mice. PLoS One. 2015;10: e0116625.

5. Illien-Junger S, Fau GF, Laudier DM, et al. Combined anti-inflammatory and anti-AGE drug treatments have a protective effect on intervertebral discs in mice with diabetes. PLoS One. 2013;8:e64302.

6. Chen S, Fau LM, Li J, et al. The correlation between microvessel pathological changes of the endplate and degeneration of the intervertebral disc in diabetic rats. Exp Ther Med. 2013;5:711-7.

7. Kong JG, Park JB, Lee D, Park EY. Effect of high glucose on stress-induced senescence of nucleus pulposus cells of adult rats. Asian Spine J. 2015;9: 155-61.

8. Maris FS, Ward KJ, latridis JC, et al. Does type 2 diabetes mellitus promote intervertebral disc degeneration?:[]]. Eur Spine J. 2016;25(9):2716-20.
9. Won HY, Park JB, Park EY, et al. Effect of hyperglycemia on apoptosis of notochordal cells and intervertebral disc degeneration in diabetic rats.[]]. Journal of Neurosurgery Spine. 2009;11(6):741.

10. Liu X, Pan F, Ba Z, et al. The potential effect of type 2 diabetes mellitus on lumbar disc degeneration: a retrospective single-center study. J Orthop Surg Res. 2018 Mar 14;13(1):52.

11. Pfirrmann CW, Dora C, Schmid MR, et al. MR image-based grading of lumbar nerve root compromise due to disk herniation: reliability study with surgical correlation. Radiology. 2004;230:583-8.

12. Hao DJ, Duan K, Liu TJ, Liu JJ, Wang WT. Development and clinical application of grading and classification criteria of lumbar disc herniation. Medicine (Baltimore). 2017;96(47):e8676

13. Milette PC. Classification, diagnostic imaging, and imaging characterization of a lumbar herniated disk. Radiol Clin N Am. 2000;38:1267-92.

14. Mysliwiec LW, Cholewicki J, Winkelpleck MD, et al. MSU classification for herniated lumbar discs on MRl: toward developing objective criteria for surgical selection. Eur Spine J. 2010;19:1087-93.

15. Chen S, Hu ZJ, Zhou ZJ, et al. Evaluation of 12 novel molecular markers for degenerated nucleus pulposus in a Chinese population. Spine (Phila Pa 1976). 2015;15:1252-60.

16. Park EY, Park JB. High glucose-induced oxidative stress promotes autophagy through mitochondrial damage in rat notochordal cells. Int Orthop. 2013: 2507-14.

17. Sakai D,Nakamura Y,Nakai T et al. Exhaustion of nucleus pulposus progenitor cells with ageing and degeneration of the intervertebral disc. Nat Commun. 2012;1264.

18. Sambrook PN, MacGregor AJ, Spector TD. Genetic influences on cervical and lumbar disc degeneration: a magnetic resonance imaging study in twins. Arthritis Rheum. 1999:42:366-72.

19. Videman T, Battié MC, Gibbons LE, et al. Disc degeneration and bone density in monozygotic twins discordant for insulin-dependent diabetes mellitus. Orthop Res. 2000;18(5):768-72.

20. Sinclair AJ, Dunning T, Dhatariya K, et al. Clinical guidelines for type 1 diabetes mellitus with an emphasis on older adults: an executive summary. Diabet Med. 2019 Sep 09. https://doi.org/10.1111/dme.14135 [Epub ahead of print].

21. Wang F, Cai F, Shi R, et al. Aging and age related stresses: a senescence mechanism of intervertebral disc degeneration. Osteoarthr Cartil. 2016;24: 398-408.

22. Chen S, Liao M, Li J, et al. The correlation between microvessel pathological changes of the endplate and degeneration of the intervertebral disc in diabetic rats. Exp Ther Med. 2013;5:711-7.

23. Alpantaki K, Kampouroglou A, Koutserimpas C, et al. Diabetes mellitus as a risk factor for intervertebral disc degeneration: a critical review. Eur Spine J. 2019 Jun;14 [Epub ahead of print].

24. Robinson D, Mirovsky $\mathrm{Y}$, Halperin N, et al. Changes in proteoglycans of intervertebral disc in diabetic patients. A possible cause of increased back pain. Spine (Phila Pa 1976). 1998;23(8):849-55.

25. Longo UG, Denaro L, Spiezia F, et al. Symptomatic disc herniation and serum lipid levels. Eur Spine J. 2011;20(10):1658-62.

26. Longo UG, Papapietro N, Petrillo S, et al. Mesenchymal stem cell for prevention and management of intervertebral disc degeneration. Stem Cells Int. 2012;2012:921053. https://doi.org/10.1155/2012/921053.

\section{Publisher's Note}

Springer Nature remains neutral with regard to jurisdictional claims in published maps and institutional affiliations.

Ready to submit your research? Choose BMC and benefit from:

- fast, convenient online submission

- thorough peer review by experienced researchers in your field

- rapid publication on acceptance

- support for research data, including large and complex data types

- gold Open Access which fosters wider collaboration and increased citations

- maximum visibility for your research: over $100 \mathrm{M}$ website views per year

At $\mathrm{BMC}$, research is always in progress.

Learn more biomedcentral.com/submission 